\title{
Qualidade do cuidado em saúde e segurança do paciente: avaliação dos resultados de um programa de formação à distância
}

\author{
Quality in healthcare and patient safety: evaluation of the results \\ of a distance learning program
}

Rosilene Aparecida dos Santos (https://orcid.org/0000-0002-4431-1244) ${ }^{1}$

Walter Vieira Mendes Júnior ${ }^{1}$ in memoriam

Mônica Martins (https://orcid.org/0000-0002-9962-0618) ${ }^{1}$

${ }^{1}$ Escola Nacional de Saúde Pública Sergio Arouca, Fundação Oswaldo Cruz. R. Leopoldo Bulhões 1480, Manguinhos. 21041-210 Rio de Janeiro RJ Brasil. rosilenasantos@gmail.com

\begin{abstract}
This paper aims to present an analysis of the Quality in Health and Patient Safety Training Program (CQSSP) results of the Sérgio Arouca National School of Public Health. This is a quantitative, qualitative, cross-sectional, and descriptive study based on the Kirkpatrick's Evaluation Model. The findings provide us with a clearer picture of the success of the CQSSP pedagogical intent through a positive assessment for the Reaction, Learning, Behavioral, Results levels. From the analysis of the perception of the graduates, we observed that $82 \%$ of them started to fully consider the occurrence of an error in the provision of care, 68\% incorporated the acquired knowledge into their professional practice, and $73 \%$ started to study and research themes related to Patient Safety (PS). We also conducted a survey on the number of Patient Safety Centers or equivalent bodies established or reformulated during or after the CQSSP. We also evaluated the extent of the contribution of the course in the implementation of Patient Safety protocols and actions in hospitals. The findings point to a significant contribution of the CQSSP to PS and the quality of hospital care.
\end{abstract}

Key words Patient safety, Health care quality, Educational evaluation, Institutional evaluation, Professional qualification
Resumo O objetivo deste artigo é apresentar uma análise dos resultados do Programa de Formação em Qualidade em Saúde e Segurança do Paciente (CQSSP) da Escola Nacional de Saúde Pública Sergio Arouca, da Fundação Oswaldo Cruz. Trata-se de uma abordagem quantitativa e qualitativa, transversal e descritiva, baseada no Modelo de Avaliação de Kirkpatrick. Os achados dimensionaram o êxito da proposta pedagógica do CQSSP com avaliação considerada positiva nos níveis de Reação, Aprendizagem, Comportamento e Resultados. A partir de análise da percepção de egressos, observou-se que $82 \%$ destes passaram a considerar plenamente a ocorrência de erro na prática do cuidado, 68\% a incorporar os conhecimentos adquiridos à sua prática profissional, e $73 \%$ passaram a estudar e pesquisar temas relacionados à segurança do paciente. Inquérito captando o número de Núcleos de Segurança do Paciente ou instâncias equivalentes constituídos ou reformulados durante ou depois do CQSSP foi realizado. Avaliou-se, ainda, o grau de contribuição do curso na implementação dos protocolos e ações de Segurança do Paciente (SP) nos hospitais, refletindo, assim, a significativa contribuição do CQSSP para a segurança do paciente e qualidade do cuidado hospitalar.

Palavras-chave Segurança do paciente, Qualidade da assistência à saúde, Avaliação educacional, Avaliação institucional, Formação profissional 


\section{Introdução}

Nas últimas décadas, cresce o debate e as ações cujas perspectivas se voltam para a prestação de um cuidado que preze pela qualidade e que seja seguro. O relatório To Err is Human, do Institue Of Medicine (IOM), dos Estados Unidos, constitui o principal marco para a segurança do paciente $(\mathrm{SP})^{1}$, esse relatório indicou que cerca de cem mil pessoas morrem, por ano, vítimas de Eventos Adversos ${ }^{2}$. A magnitude dos problemas relacionados à SP foi descrita em inúmeros estudos em países como Estados Unidos, Austrália, Reino Unido, Portugal e Brasil ${ }^{3}$.

Diversas iniciativas globais voltadas à SP foram desenvolvidas, dentre essas, destaca-se a criação em 2004, pela Organização Mundial de Saúde (OMS), da World Alliance for Patient Safety, desdobrada em um programa ${ }^{4}$, cujas linhas de ação constituíram iniciativas no campo educacional e da pesquisa, como a criação de uma taxonomia específica e as campanhas denominadas "Desafios Globais" voltadas para a redução de infecções relacionadas à assistência à saúde, à melhoria da segurança no cuidado cirúrgico e à redução dos erros relacionados à medicação $0^{5}$. Em 2020, a OMS na comemoração ao dia mundial da Segurança do Paciente lançou a campanha "Profissionais de saúde seguros, pacientes seguros", chamando a atenção para a importância dos profissionais na SP.

No Brasil, o Ministério da Saúde (MS) lançou, em 2013, o Programa Nacional de Segurança do Paciente $(\mathrm{PNSP})^{6}$, em seguida, a Agência Nacional de Vigilância Sanitária (Anvisa) instituiu as ações para a SP em serviços de saúde ${ }^{7}$. O PNSP está estruturado em quatro eixos de atuação: estímulo a uma prática assistencial segura; envolvimento do paciente na sua segurança; inclusão do tema no ensino; e incremento à pesquisa ${ }^{8}$.

A Escola Nacional de Saúde Pública Sergio Arouca (ENSP), da Fundação Oswaldo Cruz (Fiocruz), atendendo à proposta de inclusão do tema SP no ensino, em parceria com a Universidade Nova de Lisboa, desenvolveu o Curso Internacional em Qualidade em Saúde e Segurança do Paciente (CQSSP), com o objetivo de proporcionar o desenvolvimento de competências e conhecimentos científicos sobre as questões da qualidade do cuidado e da SP.

Como estratégia de uma política pública, reconhecendo o protagonismo dessa iniciativa e a relevância de sua avaliação, recorreu-se a um modelo de avaliação de processos de formação utilizado na área de Treinamento, Desenvolvi- mento e Educação (TD\&E). TD\&E constitui um sistema integrado por subsistemas, em que a avaliação é o subsistema responsável por prover informações, retroalimentar e aperfeiçoar todo o sistema9 . O modelo de avaliação em Quatro Níveis de Donald Kirkpatrick, desde 1959 encontra grande aceitabilidade em diversos tipos de organizações. Ao propor avaliar os níveis de Reação, Aprendizagem, Comportamento e Resultados, permite um olhar abrangente sobre o processo de formação e os resultados alcançados ${ }^{10}$. Ademais, tendo em vista o caráter teórico-prático da qualidade do cuidado e da SP delineado no CQSSP, o modelo de Kirkpatrick apresentou-se como uma potencial ferramenta avaliativa adequada para dimensionar a ponte entre formação e prática.

Para Shortell e Richardson (1978), o programa constitui uma intervenção como resposta organizada aos problemas de saúde, atingindo objetivos, com vistas a melhorar a saúde de uma população ${ }^{11}$. Admitindo-se o CQSSP como um programa, inserido no contexto do PNSP, sua avaliação é delineada como pesquisa avaliativa, ou seja, um procedimento que consiste em fazer um julgamento ex-post de uma intervenção usando métodos científicos ${ }^{12}$, buscando conhecer, assim, os efeitos do CQSSP na transformação da realidade e seu impacto no cuidado em saúde.

Como abordagem avaliativa retrospectiva, considerando o contexto da pandemia da COVID-19 que afetou as condições de vida das populações e impactou as organizações de saúde, o estudo agrega relevância. Esse contexto modificou as prioridades e impôs a centralidade das ações na área da saúde. Velhos e novos riscos relacionados à qualidade do cuidado e à SP emergem, assim, cursos com essa temática, na modalidade à distância, ancorado numa proposta de intervenção para melhoria do cuidado prestado, podem constituir uma estratégia que ajude a atingir metas dos Objetivos de Desenvolvimento Sustentável, contribuindo, sobretudo, com o objetivo 3 que propõe Garantir o acesso à saúde de qualidade e promover o bem-estar para todos, em todas as idades ${ }^{13}$.

Este estudo teve como objetivo avaliar o curso de especialização em qualidade em saúde e segurança do paciente (CQSSP) ofertado pela ENSP baseada no modelo de Kirkpatrick, considerando aspectos da formação, aprendizagem, prática e produção de resultados. As duas questões norteadoras foram: (i) O CQSSP como programa de intervenção produziu resultados nas organizações de saúde? (ii) Quais características foram diferenciais nessa intervenção enquanto processo 
de formação ofertado na modalidade Educação à Distância (EAD)?

\section{Método}

Trata-se de um estudo transversal com uma abordagem quantitativa de caráter descritivo que envolveu elementos qualitativos. Na abordagem quantitativa foram analisados os dados provenientes de questionário eletrônico aplicado aos egressos do CQSSP e informações disponíveis na plataforma do curso. A abordagem qualitativa se baseou em entrevistas de atores ligados ao desenvolvimento e execução do curso e na revisão da documentação do curso, com a finalidade de subsidiar a construção do questionário eletrônico.

De acordo com o modelo de avaliação aplicado, o processo de formação deve ser avaliado em quatro níveis: Reação, Aprendizagem, Comportamento e Resultados. Por se tratar de um modelo teórico classificado como genérico ${ }^{9}$ permitiu a utilização de múltiplas técnicas e instrumentos de pesquisa. A organização das informações de cada nível é apresentada no Quadro 1. Os itens que compuseram cada categoria foram mensurados por escala do tipo Likert, com cinco pontos.

O CQSSP trata-se de um curso de especialização lato sensu, oferecido pela ENSP, na modalidade à distância/semipresencial, com carga horária de 408 horas, requerendo dos profissionais participantes dedicação semanal mínima de oito horas. A primeira edição, objeto dessa análise, foi realizada entre setembro de 2014 a setembro de
2015, foram ofertadas 1.050 vagas (mil alunos do Brasil, 25 de Portugal e 25 de Países Africanos de Língua Oficial Portuguesa (PALOPS) a um público-alvo de profissionais de nível superior atuando em hospitais com duzentos ou mais leitos.

As entrevistas realizadas com o coordenador geral do curso, o coordenador pedagógico, um orientador de aprendizagem e um tutor foram baseadas em roteiros pré-estabelecidos, que buscaram respeitar a especificidade do tipo de inserção de cada ator.

A revisão documental baseou-se em registros do CQSSP que se referem à plataforma virtual, ao formulário de acompanhamento do curso (FAC), ao projeto do curso, às avaliações do curso, ao caderno do aluno e os trabalhos de conclusão de curso (TCC) elaborados em forma de planos de melhoria da SP. Para a coleta dos dados documentais foi aplicado um roteiro de extração criado para esta finalidade.

As entrevistas e revisão documental contemplaram os seguintes aspectos do CQSSP: organização e planejamento (antecedentes, necessidade, objetivos, conteúdos temáticos); estruturação e execução (coordenação, seleção de tutores, seleção dos participantes, estrutura física e recursos didáticos); avaliação (avaliação institucional de aprendizagem e avaliação institucional do curso e dos resultados); e resultados vinculados aos objetivos do curso e aos contidos no plano de trabalho.

A partir das etapas anteriores, um questionário foi elaborado e aplicado a uma amostra de conveniência composta por 52 alunos egressos

Quadro 1. Modelo em Quatro Níveis de Kirkpatrick: aspectos avaliados, categorias avaliativas, critério de escolha, e fonte de informações e dados.

\begin{tabular}{|c|l|l|l|l|}
\hline $\begin{array}{c}\text { Nível de } \\
\text { avaliação }\end{array}$ & \multicolumn{1}{|c|}{ Aspecto avaliado } & Categorias avaliativas & $\begin{array}{c}\text { Critério de escolha } \\
\text { das categorias }\end{array}$ & $\begin{array}{c}\text { Fonte de } \\
\text { informações e } \\
\text { dados }\end{array}$ \\
\hline & $\begin{array}{l}\text { A avaliação no nível } \\
\text { Reação evidencia a } \\
\text { opinião dos egressos } \\
\text { do CQSSP do estado } \\
\text { de Minas Gerais sobre } \\
\text { diversos aspectos do } \\
\text { curso. Os resultados } \\
\text { foram mensurados de } \\
\text { acordo com a Escala } \\
\text { de Likert, que sofreu } \\
\text { adaptações para melhor } \\
\text { se adequar ao alcance dos } \\
\text { objetivos da pesquisa }\end{array}$ & $\begin{array}{l}\text { Material Didático e } \\
\text { Conteúdo Programático } \\
\text { Atividades } \\
\text { Sistema de Tutoria, } \\
\text { Estrutura de Apoio a } \\
\text { Aprendizagem }\end{array}$ & $\begin{array}{l}\text { Selecionadas a } \\
\text { partir da análise } \\
\text { de conteúdo da } \\
\text { revisão documental e } \\
\text { entrevistas }\end{array}$ & $\begin{array}{l}\text { Entrevista e revisão } \\
\text { documental } \\
\text { Questionário de } \\
\text { avaliação aplicado } \\
\text { aos alunos egressos }\end{array}$ \\
\hline
\end{tabular}


Quadro 1. Modelo em Quatro Níveis de Kirkpatrick: aspectos avaliados, categorias avaliativas, critério de escolha, e fonte de informações e dados.

\begin{tabular}{|c|c|c|c|c|}
\hline $\begin{array}{c}\text { Nível de } \\
\text { avaliação }\end{array}$ & Aspecto avaliado & Categorias avaliativas & $\begin{array}{l}\text { Critério de escolha } \\
\text { das categorias }\end{array}$ & $\begin{array}{c}\text { Fonte de } \\
\text { informações e } \\
\text { dados }\end{array}$ \\
\hline 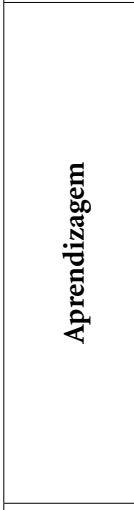 & $\begin{array}{l}\text { Neste nível se avalia o } \\
\text { conhecimento adquirido } \\
\text { pelos alunos, em } \\
\text { termos de aquisição } \\
\text { dos conhecimentos, } \\
\text { desenvolvimento das } \\
\text { habilidades propostas, e } \\
\text { capacidade de mudar de } \\
\text { atitude. Os dados foram } \\
\text { colhidos na plataforma } \\
\text { curso, e organizados em } \\
\text { tabelas e gráficos para } \\
\text { análise }\end{array}$ & $\begin{array}{l}\text { Unidades de } \\
\text { aprendizagem I, II, III, E } \\
\text { IV e TCC }\end{array}$ & $\begin{array}{l}\text { Foram compilados } \\
\text { e analisados os } \\
\text { resultados das } \\
\text { unidades de } \\
\text { aprendizagem e do } \\
\text { TCC dos alunos } \\
\text { demonstrando o } \\
\text { desempenho dos } \\
\text { alunos ao longo do } \\
\text { curso }\end{array}$ & $\begin{array}{l}\text { Avaliações } \\
\text { processuais } \\
\text { referentes a cada } \\
\text { Unidade de } \\
\text { Aprendizagem } \\
\text { (UA) disponíveis } \\
\text { no ambiente virtual } \\
\text { de aprendizagem } \\
\text { e TCC }\end{array}$ \\
\hline 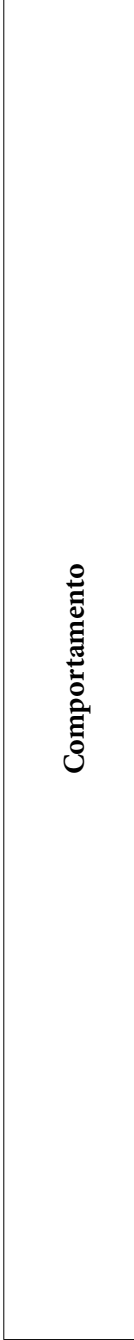 & $\begin{array}{l}\text { Diz respeito à parcela } \\
\text { de conhecimentos, } \\
\text { habilidades e atitudes que } \\
\text { são transferidas para o } \\
\text { trabalho. As mudanças de } \\
\text { comportamento foram } \\
\text { avaliadas a partir da auto- } \\
\text { percepção dos alunos } \\
\text { egressos. Os resultados } \\
\text { foram mensurados de } \\
\text { acordo com a Escala de } \\
\text { Likert adaptada }\end{array}$ & 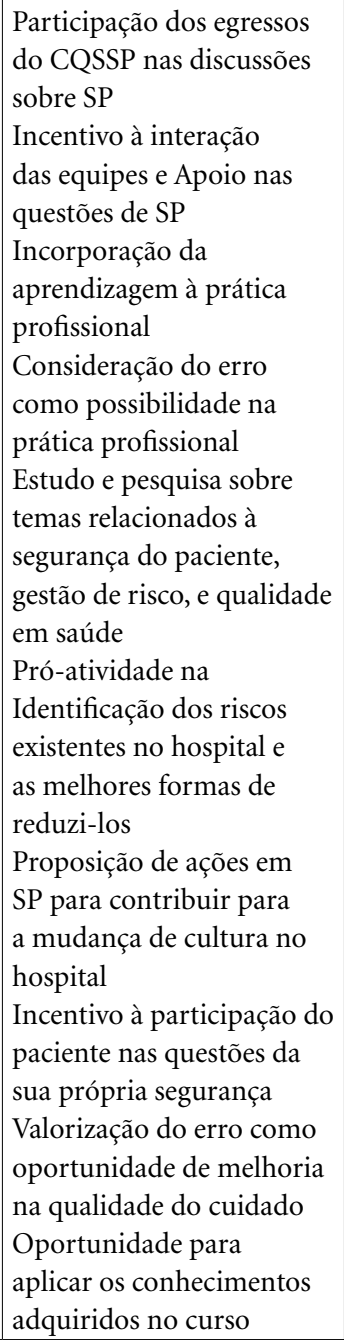 & $\begin{array}{l}\text { Através da revisão } \\
\text { documental do } \\
\text { CQSSP, e das } \\
\text { entrevistas com o } \\
\text { coordenador geral } \\
\text { do curso, com } \\
\text { o coordenador } \\
\text { pedagógico, com } \\
\text { o orientador de } \\
\text { aprendizagem } \\
\text { e o tutor, foram } \\
\text { apontadas as } \\
\text { competências } \\
\text { desejadas com } \\
\text { CQSSP, e possíveis } \\
\text { mudanças de } \\
\text { comportamento } \\
\text { esperadas com } \\
\text { o processo } \\
\text { de formação. } \\
\text { Considerando esses } \\
\text { apontamentos, } \\
\text { articulados aos } \\
\text { objetivos do CQSSP, } \\
\text { denominado } \\
\text { como perfil do } \\
\text { egresso, foram } \\
\text { inseridas questões } \\
\text { autoavaliativas } \\
\text { sobre esses } \\
\text { comportamentos } \\
\text { esperados no } \\
\text { questionário enviado } \\
\text { aos alunos }\end{array}$ & $\begin{array}{l}\text { Entrevista } \\
\text { e a revisão } \\
\text { documental. } \\
\text { Questionário de } \\
\text { avaliação aplicado } \\
\text { aos alunos egressos }\end{array}$ \\
\hline
\end{tabular}

continua

do curso no estado de Minas Gerais, selecionados para o CQSSP a partir da indicação das direções dos hospitais localizados nesse estado. A escolha do estado de Minas Gerais deveu-se ao fato de que apresentava um quadro mais estável frente às crises econômica, social e política que atingi- 
Quadro 1. Modelo em Quatro Níveis de Kirkpatrick: aspectos avaliados, categorias avaliativas, critério de escolha, e fonte de informações e dados.

\begin{tabular}{|c|c|c|c|c|}
\hline $\begin{array}{l}\text { Nível de } \\
\text { avaliação }\end{array}$ & Aspecto avaliado & Categorias avaliativas & $\begin{array}{l}\text { Critério de escolha } \\
\text { das categorias }\end{array}$ & $\begin{array}{c}\text { Fonte de } \\
\text { informações e } \\
\text { dados }\end{array}$ \\
\hline 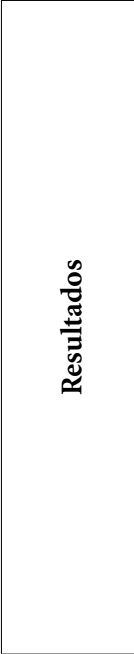 & $\begin{array}{l}\text { Teve como propósito } \\
\text { descrever as ações para a } \\
\text { segurança do paciente e } \\
\text { melhoria de qualidade do } \\
\text { cuidado implementadas } \\
\text { a partir da atuação dos } \\
\text { alunos, relacionando-as } \\
\text { com as contribuições do } \\
\text { CQSSP. Um bloco de } \\
\text { questões específicas sobre } \\
\text { resultados foi incluído } \\
\text { no questionário aplicado } \\
\text { aos alunos egressos } \\
\text { Os resultados foram } \\
\text { compilados e organizado } \\
\text { em gráficos e tabelas, para } \\
\text { análise }\end{array}$ & $\begin{array}{l}\text { Constituição e operação } \\
\text { dos Núcleos de Segurança } \\
\text { do Paciente (NSPs) } \\
\text { Sistema de notificação de } \\
\text { incidentes } \\
\text { Cultura de segurança } \\
\text { Implementação dos } \\
\text { protocolos } \\
\text { Ações de educação } \\
\text { continuada/permanente } \\
\text { Fatores contribuintes para } \\
\text { implementação das ações } \\
\text { de SP: estrutura física, } \\
\text { apoio da direção, apoio da } \\
\text { equipe, fatores externos, } \\
\text { comunicação }\end{array}$ & $\begin{array}{l}\text { As categorias } \\
\text { avaliativas foram } \\
\text { selecionadas de } \\
\text { acordo com as ações } \\
\text { propostas nos planos } \\
\text { de SP, elaborados } \\
\text { pelos alunos/equipes } \\
\text { de cada hospital nos } \\
\text { TCCs, tendo em vista } \\
\text { as normativas legais } \\
\text { dispostas na portaria } \\
\text { MS 529/2013 e } \\
\text { na RDC ANVISA } \\
\text { 36/2013 }\end{array}$ & $\begin{array}{l}\text { Entrevista e } \\
\text { revisão documental } \\
\text { Questionário de } \\
\text { avaliação aplicado } \\
\text { aos alunos egressos }\end{array}$ \\
\hline
\end{tabular}

Fonte: Elaborado pelos autores.

ram o país no momento de desenvolvimento do estudo, e que poderiam afetar consideravelmente os resultados.

O questionário semi-estruturado, enviado aos alunos egressos do CQSSP, contemplou reações e mudanças de comportamentos dos alunos, assim como resultados obtidos a partir do processo de formação. Elaborado na forma digital, utilizando como plataforma o Google Formulários, foi encaminhado via correio eletrônico para os alunos em 2017. Um protótipo inicial do questionário foi aplicado a dois alunos egressos do curso, não incluídos na amostra, para avaliação de sua clareza, abrangência e tempo despendido para a resposta.

$\mathrm{Na}$ consulta à plataforma, foram coletados dados quanto ao desempenho dos alunos nos distintos módulos do CQSSP e no trabalho de conclusão de curso. Essas informações foram utilizadas para a avaliação no nível Aprendizagem do modelo.

$\mathrm{Na}$ abordagem qualitativa da pesquisa, que envolveu as entrevistas e a revisão documental, foi utilizado como técnica a análise de conteúdo, adaptada para atender à proposta do presente estudo. Seguindo os passos propostos por Campos ${ }^{14}$ foi realizada a exploração prévia dos documentos relativos ao curso, e leitura flutuante desses e das entrevistas. Em seguida, foram selecionadas as unidades de análise, que por sua vez foram categorizadas tendo como base o referencial teórico do estudo, e que teve o objetivo de conferir validade intrínseca ao resultado da análise. O agrupamento em categorias, e/ou subcategorias, das unidades de análise foram realizados tanto por frequência, quanto por relevância implícita.

$\mathrm{Na}$ abordagem quantitativa, as informações obtidas com a aplicação do questionário e levantadas na plataforma do curso foram analisadas utilizando-se estatística descritiva. As informações quantitativas foram estratificadas segundo as variáveis categóricas: categoria profissional, tempo de profissão, exercício em cargo de gestão, participação em Núcleos de Segurança do Paciente (NSPs) e tipo de gestão do estabelecimento.

O projeto de pesquisa foi aprovado pelo Comitê de Ética em Pesquisa da ENSP.

\section{Resultados}

O CQSSP apresentava particularidades com relação às motivações e ao contexto no qual foi desenvolvido, à sua estruturação, aos seus pressupostos e instrumentos pedagógicos. Alinhado 
às iniciativas mundiais, nasceu buscando encontrar soluções para os problemas ligados à SP no Brasil, em Portugal e nos PALOPs, e associado ao interesse das Escolas de Saúde Pública do Brasil e Portugal de ampliar parceria.

A produção científica sobre SP e a experiência acumulada pelas duas escolas, já havia uma disciplina no curso stricto-sensu da ENSP e um curso em SP na escola portuguesa, foram elementos facilitadores para constituição das bases teóricas e conceituais do CQSSP que formaram o conteúdo programático, culminando na elaboração do material didático específico (Quadro 2). O conteúdo foi dividido em três grandes blocos: (i) noção teórica e histórica da SP, (ii) questões da prática assistencial sensíveis a problemas na qualidade do cuidado e SP, e (iii) medidas e ações para gerenciar os problemas de SP nas organizações.

Ao pretender uma mudança na cultura da SP nos hospitais, O CQSSP estruturou-se sobre uma clara linha de pensamento: assumir o erro como possibilidade e como condição humana, e a não culpabilização dos profissionais como as principais diretrizes das ações voltadas para a SP.

Os pressupostos metodológicos do CQSSP basearam-se na teoria das competências. Envolvendo um trabalho pedagógico interativo e contínuo, articulando teoria e prática na construção de novos conhecimentos. Assim, a realidade vivenciada pelo aluno era trazida para o contexto, potencializando o aprendizado e o desenvolvimento das competências. Havia no método ferramentas de aprendizagem que facilitavam a transferência para a prática. Destaca-se algumas especificidades metodológicas do CQSSP:

Conceito/estratégia aluno/equipe como unidade de aprendizagem: formado por quatro profissionais de um mesmo hospital, que estudavam e trabalhavam em conjunto, compartilhando o aprendizado e o trabalho;

Metodologias ativas: articulação teoria e prática;

Construção de um plano de SP pelos alunos: constituía uma singularidade do CQSSP;

Mediação pedagógica: o tutor era o "mediador" que conduzia o aluno na construção do conhecimento, valorizando sua prática e sua experiência;

Material didático: o curso se desenvolvia apoiado pelos livros, base teórica do curso;

Avaliação Processual: forma de avaliação que dizia respeito à trajetória do aluno dentro do curso, considerando seu empenho e dedicação muito mais que um produto acabado de conhecimento;
Tecnologia como facilitador do processo de formação: aposta no sentido de potencializar os recursos de aprendizagem e atingir o maior número de alunos e organizações de saúde. Visou, ainda, promover a interação entre esses atores, as instituições de ensino responsáveis e as organizações de saúde.

A avaliação feita pelos atores-chave condutores do processo de formação, a partir de suas percepções e vivências no CQSSP, foi bastante positiva, pois esses destacaram como facilitadores do processo de formação o tema - de interesse dos profissionais de saúde -, o material didático, a estrutura, o apoio docente e a estratégia aluno/ equipe. Como dificultadores do processo de formação foram apontados as crises políticas e econômicas que afetaram os hospitais, a dificuldade de trazer a gestão das instituições para dentro do curso, as dissimetrias na formação dos profissionais, as dificuldades metodológicas pela forma de ensino/aprendizado por tratar-se de um processo novo, os critérios de indicação dos participantes discricionários das direções nem sempre contemplando os profissionais mais indicados ao curso, e a sobrecarga de trabalho dos alunos que poderiam conflitar com a dedicação necessária.

A avaliação dos alunos/egressos, baseada no questionário construído segundo o Modelo em Quatro Níveis de Kirkpatrick, contabilizou a inclusão de 65\% (34 alunos) do total de 52 egressos de Minas Gerais. As perdas computadas foram de $35 \%$. Concluíram o curso 46 alunos, para os quais 45 questionários foram efetivamente aplicados e obtidas 34 respostas, que correspondeu a $76 \%$ do total.

O perfil dos 46 alunos egressos do CQSSP correspondia às orientações da coordenação do curso, pois a grande maioria eram enfermeiros (44\%), farmacêuticos (26\%) e um percentual menor de médicos (15\%). A participação de outras categorias profissionais (15\%) indicou que o tema SP é em essência multidisciplinar, como é propagado pela OMS.

Com relação aos 34 alunos que responderam ao questionário, destacamos o percentual de alunos que nunca haviam participado de instâncias responsáveis pela SP (6\%), e o elevado percentual de alunos (35\%) que participaram, mas depois saíram dos NSPs ou instâncias equivalentes (IEs). $\mathrm{O}$ perfil dos respondentes era composto, em grande parte, por profissionais experientes e com mais tempo na instituição: $44 \%$ dos participantes possuíam de 11 a 20 anos, $29 \%$ mais de 20 anos de profissão e somente $24 \%$ possuíam de 6 a 10 anos de profissão. Outra informação relevante foi 
Quadro 2. Organização curricular do Curso de Especialização em Qualidade em Saúde e Segurança do Paciente.

\begin{tabular}{|c|c|c|c|}
\hline $\begin{array}{c}\text { Unidade de } \\
\text { aprendizagem (UA) }\end{array}$ & Objetivos & Conteúdos & $\begin{array}{l}\text { Carga } \\
\text { horária }\end{array}$ \\
\hline $\begin{array}{l}\text { UA I } \\
\text { Qualidade em Saúde } \\
\text { e } \\
\text { Segurança do } \\
\text { Paciente: aspectos } \\
\text { fundamentais }\end{array}$ & $\begin{array}{l}\text { Introduzir os } \\
\text { conceitos, a } \\
\text { trajetória histórica } \\
\text { e as racionalidades } \\
\text { relacionadas à } \\
\text { segurança do paciente }\end{array}$ & $\begin{array}{l}\text { Qualidade do cuidado em saúde } \\
\text { A perspectiva histórica e principais desenvolvimentos } \\
\text { da segurança do paciente } \\
\text { Taxonomia em segurança do paciente } \\
\text { O erro e as violações no cuidado em saúde } \\
\text { Magnitude do problema e os fatores contribuintes do } \\
\text { erro e dos eventos adversos } \\
\text { Direito e segurança do paciente }\end{array}$ & 80 horas \\
\hline $\begin{array}{l}\text { UA II } \\
\text { Avaliação e gestão do } \\
\text { risco em } \\
\text { organizações } \\
\text { de saúde }\end{array}$ & $\begin{array}{l}\text { Identificar os tipos de } \\
\text { risco existentes em um } \\
\text { serviço de saúde e as } \\
\text { soluções já conhecidas } \\
\text { para mitigá-los ou } \\
\text { evitá-los }\end{array}$ & $\begin{array}{l}\text { Infecções associadas aos cuidados de saúde } \\
\text { Erros relacionados aos medicamentos } \\
\text { Cirurgia segura } \\
\text { A segurança do paciente e o diagnóstico } \\
\text { Erros relacionados ao laboratório } \\
\text { Gestão do risco de quedas, úlceras por pressão e de } \\
\text { incidentes relacionados com transfusão de sangue e } \\
\text { hemoderivados } \\
\text { Superlotação dos serviços de emergência } \\
\text { Gestão do risco não clínico } \\
\text { Maternidade segura } \\
\text { Segurança do paciente na Atenção Primária em Saúde }\end{array}$ & 96 horas \\
\hline $\begin{array}{l}\text { UA III } \\
\text { A gestão em saúde e } \\
\text { segurança do } \\
\text { paciente: } \\
\text { aspectos transversais } \\
\text { e transdisciplinares }\end{array}$ & $\begin{array}{l}\text { Desenvolver } \\
\text { capacidades para } \\
\text { gestão da segurança do } \\
\text { paciente nos serviços } \\
\text { de saúde, incluindo a } \\
\text { pesquisa na área }\end{array}$ & $\begin{array}{l}\text { Organizações de saúde seguras e fiáveis/confiáveis } \\
\text { Consequência econômica e social de erros e eventos } \\
\text { adversos em saúde } \\
\text { Acreditação e segurança do paciente } \\
\text { Cultura em segurança do paciente } \\
\text { Indicadores de segurança do paciente } \\
\text { Saúde do trabalhador, ergonomia e segurança do } \\
\text { paciente } \\
\text { Comunicação entre os profissionais de saúde e a } \\
\text { segurança do paciente } \\
\text { Envolvimento do paciente: desafios, estratégias e } \\
\text { limites } \\
\text { Aspectos mais relevantes nas investigações/pesquisas } \\
\text { em segurança do paciente }\end{array}$ & 152 horas \\
\hline $\begin{array}{l}\text { UA IV } \\
\text { Metodologia } \\
\text { científica }\end{array}$ & $\begin{array}{l}\text { Utilizar o método } \\
\text { científico para } \\
\text { conhecer a realidade } \\
\text { da sua organização e } \\
\text { desenvolver estratégias } \\
\text { que possam contribuir } \\
\text { para a melhoria da } \\
\text { segurança do paciente }\end{array}$ & $\begin{array}{l}\text { O que é o método científico } \\
\text { Pesquisas/investigações em segurança do paciente }\end{array}$ & 40 horas \\
\hline
\end{tabular}

Fonte: Caderno do Aluno do CQSSP da ENSP/Fiocruz.

a alta inserção dos egressos em cargos de gestão: $71 \%$ ocupavam cargo de gestão antes da realização do curso e $62 \%$ continuavam a ocupar cargos de gestão no momento da pesquisa.

A avaliação no nível "reação" estabeleceu categorias avaliativas, unidades de análise inseridas nessas categorias e dimensões avaliativas relativas às unidades de análise.
$\mathrm{Na}$ categoria avaliativa "material didático e conteúdo programático" a reação dos respondentes foi bastante positiva, para suas unidades de análise e dimensões avaliativas. (Tabela 1).

Quanto à categoria avaliativa "atividades", os egressos apresentaram reação positiva. Os maiores índices de desaprovação foram, na unidade de análise "atividades solicitadas no ambiente virtual 
de aprendizagem (AVA)", nas dimensões "interesse e estímulo" à busca de novas referências, em ambas as dimensões $6 \%$ dos alunos discordaram parcialmente da assertiva. A unidade de análise "fóruns e chats" apresentou menor aprovação, o percentual mais alto de desaprovação foi na dimensão que questionava a "opinião" dos alunos sobre esse tipo de atividade promover interação entre a equipe do hospital, 3\% discordaram totalmente da assertiva, $15 \%$ discordaram parcialmente e $6 \%$ nem discordaram nem concordaram (Tabela 1).

$\mathrm{Na}$ avaliação da categoria de análise "sistema de tutoria", na unidade de análise "tutoria e mediação pedagógica", a reação dos alunos foi positiva. Entretanto, nas dimensões avaliativas que questionava se o tutor utilizava boas estratégias para facilitar a aprendizagem do aluno, 15\% manteve a posição de neutralidade e 3\% discordou parcialmente; na dimensão em que foi questionado se o tutor ajudava o aluno a construir seu conhecimento ao invés de dar respostas prontas, $9 \%$ manteve-se neutro e $3 \%$ discordou parcialmente; e, se o tutor orientou bem a construção do TCC, $12 \%$ manteve-se neutro e $3 \%$ discordou parcialmente (Tabela 1 ).

Sobre a categoria "estrutura de apoio à aprendizagem" o percentual de reação negativa recaiu na qualidade da rede de dados (conexão com a internet), em que 3\% discordaram totalmente que essa fosse de boa qualidade, $6 \%$ discordaram parcialmente e $3 \%$ nem discordaram, nem concordaram com a assertiva (Tabela 1).

$\mathrm{Na}$ categoria de análise "fatores que poderiam impactar a participação dos alunos no curso", o dado mais relevante foi que $18 \%$ discordaram parcialmente de que tiveram disponibilidade para cumprir a carga horária mínima do curso de oito horas semanais (Tabela 1).

O nível "aprendizagem" inferiu que o CQSSP alcançou excelentes resultados. O desempenho individual dos alunos nas três Unidades de Aprendizagem (UAs), somado à nota individual do TCC, apontou que a média dos alunos egressos que alcançaram o conceito A (excelente) correspondeu a $69 \%, 23,9 \%$ alcançaram o conceito B (bom) e o conceito C (regular) correspondeu a $7,1 \%$ dos egressos; não houve registro de reprovação (Tabela 1). A aprendizagem por categoria profissional não apresentou variações significativas, e o desempenho aluno/equipe não variou em função da localização geográfica dos hospitais em que atuavam.

No nível "comportamento" a pesquisa indicou que o grande mote do CQSSP, valorização pelos egressos do erro como oportunidade de melhoria na qualidade do cuidado, obteve os maiores percentuais de concordância total (82\%) e parcial (15\%). Sobre a oportunidade de aplicar o que aprendeu, em sua maioria, os alunos afirmaram que tiveram oportunidade de aplicar os conhecimentos e habilidades adquiridos, foram $59 \%$ de concordância total e $35 \%$ de concordância parcial. Ademais, $68 \%$ dos profissionais concordaram totalmente, e $26 \%$ concordaram parcialmente que passaram a incorporar a aprendizagem do curso na sua prática profissional. Esses dados evidenciam mudanças de atitudes na prática profissional (Tabela 1).

O nível "resultados" tratou da contribuição do CQSSP na implementação das ações para SP nos hospitais. Observou-se que $100 \%$ constituíram os NSPs ou IEs, a maioria em plena operação (70\%). Na composição dos NSPs ou IEs, enfermeiros formavam a categoria profissional predominante presentes em $100 \%$, farmacêuticos em $90 \%$, e médicos em $80 \%$. Afora profissionais de saúde, a categoria mais frequente foi o administrador, presente em $40 \%$ dos NSPs. Todavia, a dedicação dos profissionais a esta instância, ainda, era problemática: $80 \%$ dos hospitais contavam com dedicação apenas parcial da carga horária, somente $10 \%$ possuíam profissionais exclusivamente dedicados. Grande parte dos NSPs ou IEs estavam vinculados à alta direção, ou à direção geral $(30 \%)$ ou à direção clínica/técnica (50\%). No que diz respeito à articulação dos NSPs, ou IEs, com as instâncias superiores, metade só se reunia com instâncias superiores quando necessário. Em $40 \%$ dos hospitais essas reuniões eram periódicas e em $10 \%$ a situação era mais crítica, com reuniões esporádicas. Quanto à contribuição do CQSSP, percebeu-se que a grande maioria dos NSPs, ou IEs, já se encontravam constituídas antes do curso (70\%). Entretanto, 20\% foram constituídos durante ou depois do curso e $10 \%$ foram reformulados durante ou depois do curso.

O sistema de notificações encontrava-se em funcionamento em $90 \%$ dos hospitais, em sua maior parte sob a responsabilidade dos NSPs ou IEs. $20 \%$ dos hospitais implementou o sistema durante ou depois da realização do curso, além de $30 \%$ terem sido aperfeiçoado no mesmo período. No geral, em $80 \%$ dos hospitais as notificações seguiam as orientações da ANVISA.

Os dados indicaram que $40 \%$ dos NSPs ou IEs dedicavam mais de $50 \%$ do tempo às notificações, e $20 \%$ utilizavam entre $20 \%$ a $50 \%$ do tempo com as notificações. No que diz respeito à cultura de segurança, fundamental para construir sistemas de cuidado seguros, observou-se 


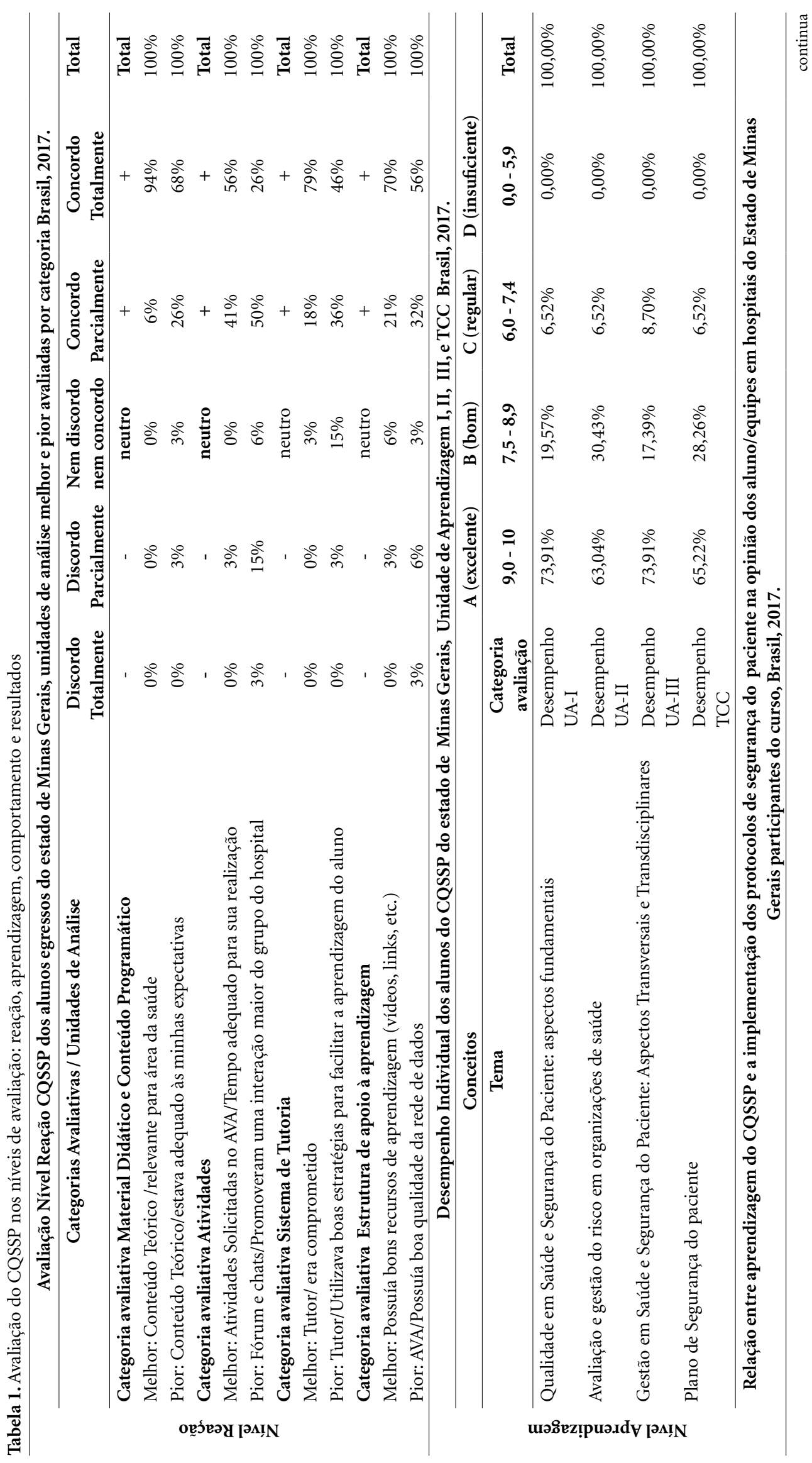




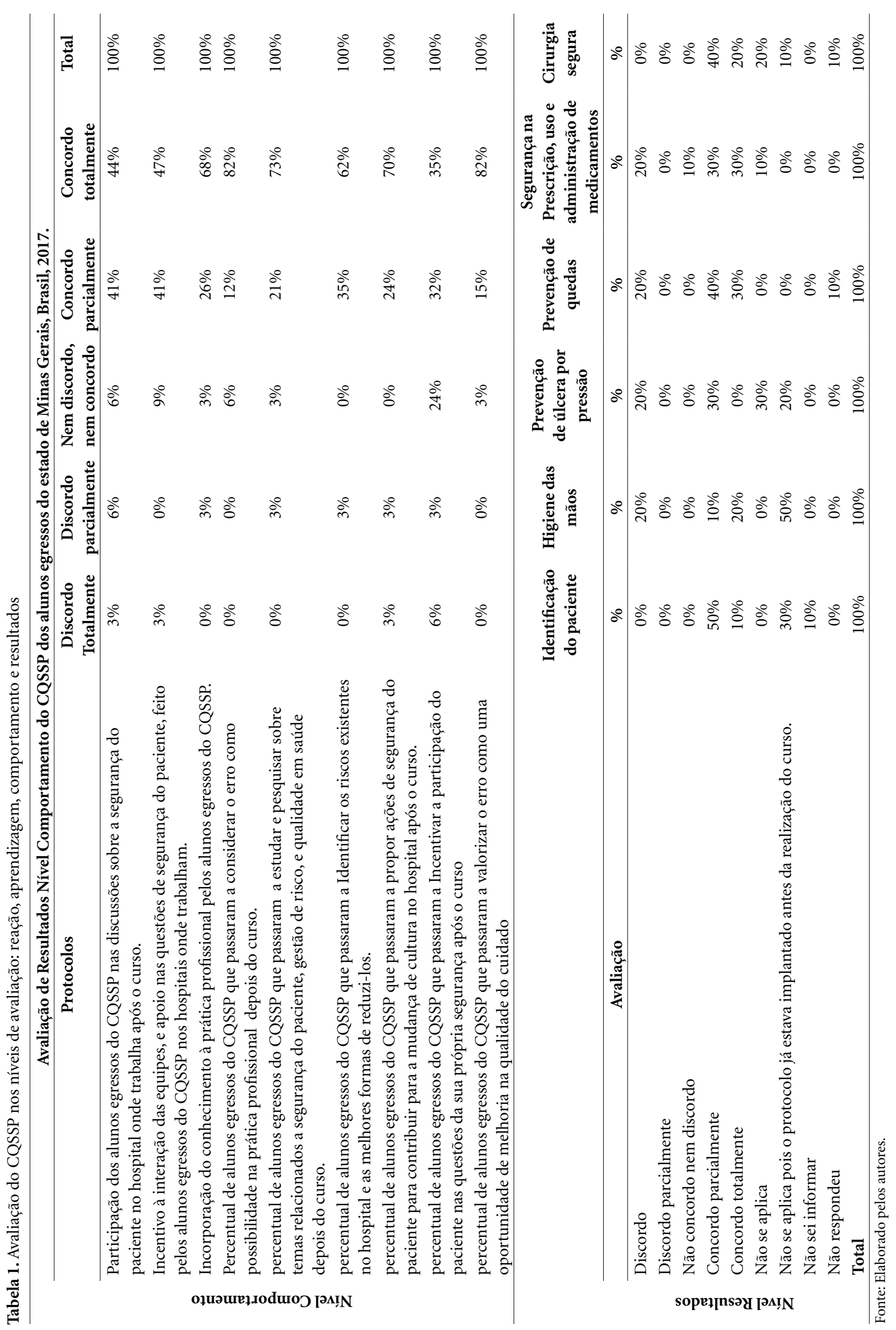


que $40 \%$ dos alunos/equipes aplicaram questionário para medir a cultura de segurança.

O protocolo de identificação do paciente encontrava-se completamente implementado em $50 \%$ dos hospitais, em 30\% estava implementado, mas não monitorado, e em $20 \%$ parcialmente implementado (Tabela 2). Sobre a contribuição do CQSSP para implementação desse protocolo houve reconhecimento da contribuição parcial em 50\% dos hospitais, e contribuição total em $10 \%$ deles (Tabela 2)

O protocolo de higienização das mãos estava completamente implementado em $60 \%$ dos hospitais, em $40 \%$ implementado e não monitorado (Tabela 2). Sobre a relação entre aprendizado e a implementação, o índice de concordância total foi de $20 \%$ e parcial de $10 \%$, metade dos hospitais não reconheceu haver relação entre aprendizado e a implementação do protocolo, pois este já se encontrava implementado antes da realização do CQSSP, sendo que 20\% discordam da existência dessa relação (Tabela 1 ).

O protocolo de prevenção de úlceras por pressão encontrava-se planejado e não implementado em $30 \%$ dos hospitais e em $10 \%$ não estava planejado (Tabela 2). Sobre a relação entre aprendizagem do CQSSP e a implementação deste protocolo, 30\% dos alunos reconheceram parcialmente essa relação. (Tabela 1).

A implementação do protocolo de prevenção de quedas encontrava-se totalmente concluída em $50 \%$ dos hospitais, em $10 \%$ parcialmente implementado, em 20\% encontrava-se implementado e não monitorado. Somente em $20 \%$ dos hospitais esse protocolo estava planejado e não implementado (Tabela 2 ). A relação entre a aprendizagem do CQSSP e a implementação deste protocolo foi bem marcada na opinião dos alunos/equipes: $30 \%$ concordaram totalmente e $40 \%$ concordaram parcialmente, contra $20 \%$ de discordância sobre a existência dessa relação (Tabela 1).

O protocolo de segurança na prescrição, uso e administração de medicamentos encontravase completamente implementado em $60 \%$ dos hospitais e em $20 \%$ encontrava-se planejado e não implementado. Somente $20 \%$ dos hospitais o protocolo não estava planejado (Tabela 2). Houve também expressivo reconhecimento de relação entre aprendizagem do CQSSP e a implementação do protocolo, 30\% concordaram totalmente com essa relação e 30\% concordaram parcialmente. $\mathrm{O}$ percentual de discordância foi de $20 \%$ do total (Tabela 1 ).

Na implementação do protocolo de Cirurgia Segura, este foi declarado como completamente implementado em $40 \%$ dos hospitais, em $30 \%$ parcialmente implementado e em 20\% implementado e não monitorado. Esse protocolo não se encontrava planejado em somente $10 \%$ dos hospitais (Tabela 2). Na opinião dos alunos/equipes a relação entre aprendizagem do CQSSP e a implementação do protocolo de cirurgia segura foi positiva, $20 \%$ concordaram totalmente e $40 \%$ concordam parcialmente. Apenas 10\% indicaram que esse item não se aplicava porque o protocolo já estava implementado antes do CQSSP (Tabela 1).

Tabela 2. Grau de implementação dos protocolos de segurança do paciente, em hospitais do estado de Minas Gerais participantes do CQSSP, Brasil, 2017.

\begin{tabular}{|c|c|c|c|c|c|c|}
\hline Protocolos & $\begin{array}{c}\text { Não } \\
\text { Planejado }\end{array}$ & $\begin{array}{c}\text { Planejado } \\
\text { e não } \\
\text { Implementado }\end{array}$ & $\begin{array}{l}\text { Parcialmente } \\
\text { Implementado }\end{array}$ & $\begin{array}{c}\text { Implementado } \\
\text { e não } \\
\text { Monitorado }\end{array}$ & $\begin{array}{l}\text { Completamente } \\
\text { Implementado }\end{array}$ & Total \\
\hline $\begin{array}{l}\text { Identificação do } \\
\text { paciente }\end{array}$ & $0 \%$ & $0 \%$ & $20 \%$ & $30 \%$ & $50 \%$ & $100 \%$ \\
\hline Higiene das mãos & $0 \%$ & $0 \%$ & $0 \%$ & $40 \%$ & $60 \%$ & $100 \%$ \\
\hline $\begin{array}{l}\text { Prevenção de úlcera por } \\
\text { pressão }\end{array}$ & $10 \%$ & $30 \%$ & $30 \%$ & $0 \%$ & $30 \%$ & $100 \%$ \\
\hline Prevenção de quedas & $0 \%$ & $20 \%$ & $10 \%$ & $20 \%$ & $50 \%$ & $100 \%$ \\
\hline $\begin{array}{l}\text { Segurança na } \\
\text { Prescrição, uso e } \\
\text { administração de } \\
\text { medicamentos }\end{array}$ & $20 \%$ & $20 \%$ & $0 \%$ & $0 \%$ & $60 \%$ & $100 \%$ \\
\hline Cirurgia segura & $10 \%$ & $0 \%$ & $30 \%$ & $20 \%$ & $40 \%$ & $100 \%$ \\
\hline
\end{tabular}


Sobre as ações de educação continuada e permanente, ações sistemáticas com políticas e programas formais, que contemplassem todas as categorias profissionais, era uma situação existente em apenas 30\% dos hospitais. Acerca do reconhecimento da influência do CQSSP sobre as ações de educação continuada e permanente, $70 \%$ dos alunos/equipes afirmaram que embora ações já existissem antes do curso, essas foram intensificadas durante ou depois do CQSSP, e em $10 \%$ elas foram implementadas por influência do CQSSP (Tabela 1).

No que diz respeito aos fatores contribuintes que afetaram a implementação das ações de SP, na percepção dos alunos sobre a infraestrutura hospitalar, $9 \%$ discordam totalmente e $41 \%$ discordam parcialmente de que essa favorecesse a prestação de um cuidado seguro.

$\mathrm{Na}$ avaliação da influência dos fatores contribuintes externos (políticos, sociais, econômicos etc.) sobre a implementação das ações em SP, $62 \%$ concordaram totalmente e $17 \%$ parcialmente com a influência desses fatores externos.

Nos hospitais pesquisados, o apoio da direção foi sentido pela maior parte dos alunos egressos: $32 \%$ de concordância parcial e $38 \%$ de concordância total. No que tange às reuniões entre os NSPs ou IEs com os níveis de gestão superiores $40 \%$ afirmaram que participam periodicamente, e $50 \%$ participam somente quando necessário. Todavia, 32\% dos alunos concordaram totalmente e $44 \%$ parcialmente de que há participação do NSP ou IEs nas deliberações dos hospitais, os percentuais de discordância foram de $12 \%$ parcial e $6 \%$ total.

Sobre a contribuição do fator comunicação entre os NSPs, ou IEs, e outros profissionais chamou atenção que $32 \%$ dos egressos concordaram totalmente e $56 \%$ concordaram parcialmente de que esse fator contribuiu para a implementação das ações em SP (Tabela 3).

\section{Discussão}

Avaliar implica inferir um juízo de valor a partir da mensuração das propriedades de um objeto9. Um ponto fundamental a ser ressaltado, é que a avaliação do CQSSP não diz respeito somente ao processo formativo, mas principalmente aos seus resultados.

No nível "reação", pode-se inferir que o CQSSP abriu horizontes para uma boa aprendizagem, alcançando uma avaliação positiva dos alunos egressos. Entretanto, chamou a atenção os percentuais mais baixos de aprovação na unidade de análise "fóruns e chats", um achado que merece atenção, já que os chats e fóruns em curso EAD são consideradas ferramentas importantes para promover a interação do grupo. Também chama a atenção a avaliação das Estratégias que o Tutor Utilizou Para Facilitar a Aprendizagem do Aluno, a Utilização dos Recursos Disponíveis no Curso para Estabelecer Relação entre a Teoria e a Prática, e a Orientação do Tutor na Construção do TCC, como os percentuais de desaprovação e neutralidade foram mais altos, essas unidades de análise também devem constituir importante ponto de atenção.

No que diz respeito a avaliação no nível Aprendizagem, Kirkpatrick e Kirkpatrick ${ }^{10}$ afirmam que a medição do aprendizado deve determinar os conhecimentos que foram adquiridos, habilidades que foram desenvolvidas, ou atitudes modificadas, visto que para que haja mudança de comportamento pelo menos um desses pontos deve ter sido alcançado. No entanto, o alcance de qualquer um deles não implica essencialmente em mudança de comportamento. Abbad et al. ${ }^{9}$ associando os conceitos de aprendizagem em psicologia e em linguagem comum, ao citar Michaelis (2002) e Pozo (2002), destacaram que a aprendizagem resulta de processos associativos e construtivos e como tal, permitem a aquisição de diferentes tipos de resultados de aprendizagem, desde a aprendizagem de fatos, comportamentos até a aprendizagem social, verbal, conceitual e de procedimento que ao final resultará em mudanças em estruturas de conhecimento e criação de novas soluções para problemas. Fato que na transferência para o trabalho a aprendizagem envolverá a aquisição, a retenção e a generalização do conhecimento 9 . Pode-se afirmar que o CQSSP em termos de aprendizagem obteve sucesso no seu empreendimento, condição essencial para mudanças nos níveis de comportamento e de resultados, indicado pelo bom desempenho dos alunos nos módulos do curso e nos TCCs.

Segundo Kirkpatrick e Kirkpatrick ${ }^{10}$, o comportamento tem a ver com a parcela de conhecimentos, habilidades e atitudes que é transferida para o trabalho. Vale frisar que, embora seja afirmado que o comportamento no cargo não faça sentido para cursos a distância, por não serem normalmente oferecidos por organização diferente daquela com a qual os alunos possuem vínculos empregatícios, preferindo-se utilizar o termo transferência de treinamento, na pesquisa, a expressão "comportamento" foi mantida, buscando fidelidade ao modelo de avaliação uti- 
Tabela 3. Fatores contribuintes na implementação das ações para segurança do paciente nos hospitais do estado de Minas Gerais, Brasil, 2017.

\begin{tabular}{|c|c|c|c|c|c|c|}
\hline Fatores contribuintes & $\begin{array}{c}\text { Discordo } \\
\text { Totalmente }\end{array}$ & $\begin{array}{c}\text { Discordo } \\
\text { parcialmente }\end{array}$ & $\begin{array}{c}\text { Nem } \\
\text { discordo, nem } \\
\text { concordo } \\
\end{array}$ & $\begin{array}{c}\text { Concordo } \\
\text { parcialmente }\end{array}$ & $\begin{array}{c}\text { Concordo } \\
\text { totalmente }\end{array}$ & Total \\
\hline $\begin{array}{l}\text { A infraestrutura física } \\
\text { favorece um cuidado seguro }\end{array}$ & $9 \%$ & $41 \%$ & $9 \%$ & $26 \%$ & $15 \%$ & $100 \%$ \\
\hline $\begin{array}{l}\text { Apoio da direção na } \\
\text { implementação das ações } \\
\text { para segurança do paciente, }\end{array}$ & $0 \%$ & $24 \%$ & $6 \%$ & $32 \%$ & $38 \%$ & $100 \%$ \\
\hline $\begin{array}{l}\text { Fatores externos (decisões } \\
\text { políticas, economia, regulação } \\
\text { etc.) influenciaram na } \\
\text { implementação das ações } \\
\text { para segurança do paciente }\end{array}$ & $6 \%$ & $6 \%$ & $9 \%$ & $17 \%$ & $62 \%$ & $100 \%$ \\
\hline $\begin{array}{l}\text { Participação do NSP ou } \\
\text { instância equivalente das } \\
\text { deliberações favorecendo a } \\
\text { implementação das ações de } \\
\text { segurança do paciente }\end{array}$ & $6 \%$ & $12 \%$ & $6 \%$ & $44 \%$ & $32 \%$ & $100 \%$ \\
\hline $\begin{array}{l}\text { A comunicação entre os } \\
\text { membros do NSP ou } \\
\text { instância equivalente e outros } \\
\text { profissionais favoreceu a } \\
\text { implementação das ações de } \\
\text { segurança do paciente }\end{array}$ & $0 \%$ & $12 \%$ & $0 \%$ & $56 \%$ & $32 \%$ & $100 \%$ \\
\hline
\end{tabular}

lizado, embora a instituição de ensino não seja a mesma organização de trabalho dos egressos.

Ademais, o nível "comportamento" constituiu um dos mais importantes pontos da avaliação. Em primeiro lugar, por ter sido delineado a partir do que se denominou "perfil dos alunos egressos" e representou, em termos, o sucesso ou insucesso do processo formativo e dos seus objetivos. De outra maneira, representou a condição necessária para que as transformações desejadas fossem realizadas na prática e se transformassem em resultados.

De acordo com a autoavaliação positiva dos alunos, o aprendizado foi transferido para sua prática laboral. Cabe destacar que para promover a SP, a qualidade do cuidado e impulsionar a cultura de segurança nas organizações, é primordial que os profissionais envolvidos no cuidado estejam profundamente comprometidos com essas questões, pois a cultura de segurança é produto de valores, atitudes, percepções, competências, padrões de comportamento individuais e em grupos $^{4}$.

O nível "resultados" é considerado por Kirkpatrick e Kirkpatric ${ }^{10}$ o mais difícil do processo de avaliação, dada a dificuldade de se relacionar estes de forma direta com o processo de formação. Nem sempre é possível obter provas concretas de que o resultado advém do processo formativo, mas é possível obter indícios. Passados três anos desde o início do CQSSP, pode-se considerar que houve tempo razoável para avaliar a implementação das ações de SP descritas nos Planos de Segurança do Paciente dos hospitais.

Em todos os hospitais participantes, os NSPs, ou IEs, estavam constituídos e em plena operação, ou mais ou menos operantes, neste caso uma minoria. Os NSPs tem papel fundamental na implementação e articulação das ações para SP, bem como tem a prerrogativa de transformar em aprendizado e em mudanças organizacionais as demandas, vivências e experiências individuais dos profissionais no processo do cuidado, na medida em que analisa, e atua sobre a ocorrência dos incidentes em saúde, ao mesmo tempo em que cria mecanismos para converter problemas e soluções em diretrizes e políticas organizacionais. Há, nisso, indícios positivos de que existe uma parcela de contribuição do CQSSP, já que parte dessas instâncias foram constituídas ou reformuladas durante o curso. Grande parte estavam vinculadas à alta gestão, em concordância com a recomendação da $\mathrm{ANVISA}^{7}$ de que o coor- 
denador do NSP, ou IEs, deva ter assento nas instâncias deliberativas. Quanto mais próximas dos níveis de decisão, mais estratégicas e capilarizadas podem se tornar as ações de SP na organização. Todavia, a dedicação dos profissionais ao NSP ou IEs, ainda é problemática. Na maioria dos hospitais, os profissionais do núcleo dedicavam apenas parte da carga horária, somente pequena parcela possuía profissionais exclusivamente dedicados. Esse fato pode ocorrer por duas razões, a existência de profissionais em número reduzido, ou o NSP ainda não ser visto com a devida importância. Independente das razões, o fato é que isso pode gerar sobrecarga de trabalho, o profissional não se dividirá entre várias tarefas sem o risco de comprometer a qualidade do trabalho.

A aproximação dos NSPs, ou IEs, com outros setores se mostrou bastante tímida, isso pode dificultar a capilarização das ações em SP e a disseminação da cultura de segurança. Há uma maior aproximação dos NSPs ou IEs com áreas afins como as comissões de infecção hospitalar, de farmácia e terapêutica, de revisão de óbito e análise de prontuário, mas pouca aproximação com outros setores hospitalares.

O Sistema de Notificações encontrava-se em funcionamento na maioria dos hospitais, em sua maior parte sob a responsabilidade dos NSPs ou IEs. Todavia, no tocante a contribuição do CQSSP para implementação do sistema de notificações, merece atenção o fato de que 30\% declararam não reconhecer qualquer contribuição do curso. Havia por parte da coordenação a preocupação de que os NSPs ou IEs ocupassem a maior parte do tempo com o sistema de notificações, quando se reconhecia a importância de participar da política interna, e assim fomentar a SP como prioridade. A análise dos dados indicou que a situação desejada não se concretizou.

Sobre a contribuição do CQSSP para mudança na cultura de segurança do paciente, os achados foram inconclusivos, dado o desenho do presente estudo. Fato que a maioria dos hospitais não apresentou preocupação em medir a sua cultura de segurança por meio da aplicação de questionários.

A avaliação do CQSSP, no nível "resultados", para a categoria "implementação dos protocolos" de SP, favorece a conclusão de que o curso colaborou, em maior ou menor grau, para adoção dos referidos protocolos. Diante das informações coletadas torna-se evidente essa contribuição. A implementação do protocolo de segurança na prescrição, uso e administração de medicamentos apresentou um dos melhores resultados.
Sobre as ações de educação continuada e permanente, fundamentais para promover a SP nos hospitais, disseminando o conhecimento e fortalecendo uma cultura que preze pela SP e pela qualidade do cuidado, os achados mostraram que, embora essas ações existissem nos hospitais pesquisados, ainda era necessária maior sistematização, com políticas e programas formais que contemplem todas as categorias profissionais, situação existente em pequena parte dos hospitais pesquisados.

$\mathrm{Na}$ percepção dos alunos egressos, a metade dos hospitais pesquisados não oferecia uma infraestrutura que favorecesse a oferta de um cuidado seguro. O "apoio" das direções, outro fator de suma importância, foi sentido pela maior parte dos alunos egressos. Uma direção que se compromete com as questões de SP, imprime legitimidade aos NSPs e reforça importância da SP. Os fatores externos: políticos, econômicos, sociais e culturais, também atuam sobre as organizações. A crise política e econômica que se instalou no país nos últimos anos, afetou a implementação das ações em SP nos hospitais. No tocante às reuniões sistemáticas entre os NSPs, ou IEs, com os níveis superiores, trata-se de um ponto sensível. Todavia, a baixa sistematização não parece afetar a participação do NSPs, ou IEs, nas deliberações dos hospitais. A comunicação entre os NSPs, ou IEs, e outros profissionais, enquanto fator contribuinte, exerceu influência significativa na implementação das ações em SP, isso é um fator relevante, levando-se em conta que a mudança de cultura passa pela sensibilização e pelo diálogo aberto com todos os profissionais.

Alguns limites se apresentaram para o estudo em função do curto espaço de tempo para execução, da distância da localização geográfica da amostra, e da adaptação do modelo para alcançar os objetivos da pesquisa por ser posterior à realização do curso.

\section{Considerações finais}

O presente estudo ressalta a importância e a potencialidade de cursos de especialização que conjugam os eixos acadêmico e a perspectiva de transformação na prática, ofertados na modalidade EAD. A partir desta avaliação, pode se afirmar que o CQSSP foi exitoso. Ao analisá-lo, desde o momento de sua concepção até os resultados descritos, foi possível dimensionar o alcance dos seus objetivos enquanto processo de formação e programa que visou contribuir com 
a melhoria da qualidade do cuidado e SP. Tendo formado 855 alunos, distribuídos por 50 turmas no território nacional, forneceu aos egressos subsídios que resultaram em ações transformadoras da prática, que por sua vez representam o alicerce para a uma virada cultural nas organizações no que diz respeito à difícil tarefa da promoção de um cuidado seguro e de melhor qualidade. Contudo, continuidade é um elemento central para a sustentabilidade desses avanços.

Considera-se, ainda, como importante contribuição, a adaptação e aplicação do modelo que pode representar a gênese de uma abordagem metodológica para avaliação de resultados de cursos com a mesma essência, ou similaridade do CQSSP.

Após a edição da primeira experiência, analisada neste estudo, esta proposição deu lugar a três chamadas subsequentes, contudo com recorte específico e por demanda externa à ENSP. Assim, em 2016 foi ofertado o Curso de Especialização em Segurança do Paciente para Profissionais da Rede de Atenção às Urgências e Emergências; em 2017, desenvolveu-se o Curso de Aperfeiçoamento em Segurança do Paciente em Maternidades. Ambas foram ofertados por demanda do Ministério da Saúde. Em 2019, o CQSSP foi realizado em parceria com a Anvisa, destinado a profissionais de hospitais públicos e filantrópicos, com porte superior a cem leitos, das Secretarias de Estado de Saúde, da Anvisa e do Ministério da Saúde. Assim, o CQSSP permanece no catálogo da EAD da ENSP, mas é realizado sob demanda e por meio de parceria com outros órgãos, sempre voltado para fortalecer a SP no âmbito do Sistema Único de Saúde.

\section{Colaboradores}

RA Santos colaborou na concepção e delineamento, análise e interpretação de dados, redação e aprovação da versão final do artigo. WV Mendes Júnior colaborou na concepção e delineamento, e análise e interpretação de dados. M Martins fez a revisão crítica e aprovou a versão final do artigo.

\section{Agradecimento}

Ao Conselho Nacional de Desenvolvimento Científico e Tecnológico (CNPq), PQ 306100/2019-3.

O Artigo foi extraído da dissertação "Avaliação dos resultados de um programa de formação em qualidade em saúde e segurança do paciente em hospitais do estado de Minas Gerais", apresentada na Escola Nacional de Saúde Pública Sergio Arouca (ENSP), da Fundação Oswaldo Cruz (Fiocruz), em 2018. 


\section{Referências}

1. Trindade L, Lage MJ. A perspectiva histórica e principais desenvolvimentos da segurança do paciente. In: Sousa P, Mendes W, organizadores. Segurança do Paciente: conhecendo os riscos nas organizações de saúde. Rio de Janeiro: Editora Fiocruz; 2014.

2. Institute of Medicine (US) Committee on Quality of Health Care in America. Kohn LT, Corrigan JM, Donaldson MS, editors. To Err is Human: Building a Safer Health System. Washington (DC): National Academies Press (US); 2000. PMID:25077248.

3. Martins M. Qualidade do cuidado em saúde. In: Sousa P, Mendes W, organizadores. Segurança do Paciente: conhecendo os riscos nas organizações de saúde. Rio de Janeiro: Fiocruz; 2014. p. 25-38.

4. Reis CT, Martins M, Laguardia J. A segurança do paciente como dimensão da qualidade do cuidado de saúde: um olhar sobre a literatura. Cien Saude Coletiva 2013;18(7):2029-2036.

5. Mendes WV, Noronha J. Qualidade de Serviços de Saúde no SUS - Relatório Final. Telma Ruth Pereira, coord. edit.; 2013.

6. Brasil. Ministério da Saúde (MS). Portaria no 529, de $1^{\circ}$ de abril de 2013. Institui o Programa Nacional de Segurança do Paciente. Diário Oficial da União, Poder Executivo, Brasília, DF, n. 62, p. 43-44, 02 abr. 2013. Seção 1.

7. Brasil. Agência Nacional de Vigilância Sanitária (Anvisa). Resolução da Diretoria Colegiada no 36, de 25 de julho de 2013. Institui ações para a segurança do paciente em serviços de saúde e dá outras providências. Diário Oficial da União, Brasília, DF, n. 143, p. 32-3, 26 jul. 2013. Seção 1.

8. Brasil. Ministério da Saúde (MS). Fundação Oswaldo Cruz. Agência Nacional de Vigilância Sanitária. Documento Referência para o Programa Nacional de Segurança do Paciente. Brasília: MS; 2014.

9. Abbad GS, Mourão L, Meneses PPM, Zerbini T, Borges-Andrade JE, Vilas-Boas R. Medidas de avaliação em treinamento, desenvolvimento e educação: ferramentas para gestão de pessoas. Porto Alegre: Artmed; 2012.
10. Kirkpatrick DL, Kirkpatrick JD. Como avaliar programas de treinamento de equipes: os quatro niveis. Tradução José Henrique Lamensdorf. Rio de Janeiro: Senac Rio; 2010.

11. Caldas BM. Implementação do Programa Nacional de Segurança do Paciente em hospitais públicos: uma avaliação qualitativa [tese]. Rio de Janeiro: Fundação Oswaldo Cruz / Escola Nacional de Saúde Pública Sergio Arouca; 2017.

12. Hartz ZMA, organizador. Avaliação em Saúde: dos modelos conceituais à prática na análise da implantação de programas.Rio de Janeiro: Editora Fiocruz; 1997.

13. Nações Unidas Brasil. Os objetivos de Desenvolvimento Sustentável no Brasil. [acessado 2020 out 28]. Disponível em: https://brasil.un.org/pt-br/sdgs.

14. Campos CJ. Método de análise de conteúdo: ferramenta para a análise de dados qualitativos no campo da saúde. Rev Bras Enf 2004; 57(5):611-614.
Artigo apresentado em 20/11/2020

Aprovado em 22/05/2021

Versão final apresentada em 24/05/2021

Editores-chefes: Romeu Gomes, Antônio Augusto Moura da Silva 